Tropical Journal of Pharmaceutical Research October 2020; 19 (10): 2097-2101

ISSN: $1596-5996$ (print); 1596-9827 (electronic) (C) Pharmacotherapy Group, Faculty of Pharmacy, University of Benin, Benin City, 300001 Nigeria.

\title{
Ghrelin attenuates avascular necrosis of the femoral head induced by steroids in rabbits
}

\author{
Laigang Huang\#, Fanshuo Zeng\#, Baojuan Cui, Daoqing Wang, Min Sun, \\ Benling Liu, Qiangsan Sun* \\ The Second Hospital, Cheeloo College of Medicine, Shandong University, Shandong Province, 250033, China
}

*For correspondence: Email: sunqsan@126.com; Tel: +8615153169297

Sent for review: 23 March 2020

Revised accepted: 26 April 2020

\begin{abstract}
Purpose: Ghrelin is an endogenous ligand for growth hormone secretagogue receptor. The current study was aimed at examining the effect of ghrelin on avascular necrosis of the femoral head (ANFH) induced by steroids in a rabbit model and also exploring the underlying mechanism.

Methods: Experimental rabbits were separated into three groups: Control, Vehicle and Ghrelin. We established a steroid-induced ANFH model in rabbits. Then, MRI scanning and hematoxylin-eosin staining (HE) were conducted to see ANFH. The mRNA levels of Vascular Endothelial Growth Factor (VEGF) and Bone Morphogenetic Protein 2 (BMP-2) were evaluated using real-time qRT-PCR.

Results: Rabbits in the Vehicle group showed increased empty bone lacunae, reduced bone trabecula in femoral head; the number of hematopoietic cells in the bone marrow was reduced, whereas number of adipocytes increased with evident fusion phenomenon in comparison with the Control group. All of the changes induced in Vehicle group were attenuated in Ghrelin group. MRI scanning showed obvious necrosis of femoral head in the Vehicle group and less in the Ghrelin group. The mRNA levels of VEGF and BMP-2 were raised in Vehicle group and further enhanced in Ghrelin group.

Conclusion: Ghrelin attenuates steroid-induced avascular necrosis in femoral head in rabbit model. A possible mechanism may be through VEGF/BMP-2 axis.
\end{abstract}

Keywords: ANFH, BMP-2, Ghrelin, VEGF

\begin{abstract}
This is an Open Access article that uses a funding model which does not charge readers or their institutions for access and distributed under the terms of the Creative Commons Attribution License (http://creativecommons.org/licenses/by/4.0) and the Budapest Open Access Initiative (http://www.budapestopenaccessinitiative.org/read), which permit unrestricted use, distribution, and reproduction in any medium, provided the original work is properly credited.
\end{abstract}

Tropical Journal of Pharmaceutical Research is indexed by Science Citation Index (SciSearch), Scopus, International Pharmaceutical Abstract, Chemical Abstracts, Embase, Index Copernicus, EBSCO, African Index Medicus, JournalSeek, Journal Citation Reports/Science Edition, Directory of Open Access Journals (DOAJ), African Journal Online, Bioline International, Open-J-Gate and Pharmacy Abstracts

\section{INTRODUCTION}

Avascular necrosis of the femoral head (ANFH) is a progressive and disabling illness, which eventually results in femoral head collapse and hip arthroplasty [1]. Corticosteroid and alcohol are among the most common risk factors for ANFH. To date, multiple mechanisms have been proposed for the pathogenesis of ANFH, including local microvascular disturbance, dyslipidemia, and imbalance between osteoblasts and osteoclasts activities [2]. So far, no effective therapy is available for the treatment of ANFH, except prosthetic replacement.

Ghrelin is a gut-derived peptide hormone, which is initially discovered as the ligand for growth hormone secretagogue receptor. Apart from its ability to promote growth hormone, ghrelin plays an important role in food intake regulation and 
energy metabolism [3-6]. Increasing evidence displays the functions of ghrelin in bone metabolism. In vitro studies have shown that ghrelin stimulates osteoblast proliferation and differentiation, although, it has an inhibitory effect on murine osteoclast differentiation $[7,8]$. It is well known that growth hormone plays an essential role in postnatal bone growth [9], and thus ghrelin may regulate bone metabolism indirectly through stimulating growth hormone release. Moreover, recent studies showed that ghrelin benefited cardiovascular system [10], and protected heart from ischemia-reperfusion injury [11]. An experimental study showed ghrelin protection against ischemic necrosis in musculocutaneous tissues and improved local microcirculation [12].

Given the above evidence, we hypothesized that ghrelin may play a role in the avascular necrosis of the femoral head. In this study, we examined the effect of ghrelin on steroid-induced ANFH in a rabbit model, and explored the possible mechanism.

\section{EXPERIMENTAL}

\section{Reagent used for the study}

Ghrelin was purchased from Biovision (BioVisionlnc; San Francisco, USA). SoluMdrol $^{\mathrm{TM}}$ Methylprednisolone (Pharmacia \& Upjohn, Belgium), Horse serum (Sigma, USA); RNAios Plus (Takara Biotechnology, Dalian, China); PrimeScript RT reagenKit (Takara Biotechnology, Dalian, China) and SYBR Premmix EX TaqTM (Takara Biotechnology, Dalian, China) were purchased from standard suppliers.

\section{Establishment of avascular necrosis of femoral head model}

All the animal experiments were conducted according to the Principles of Laboratory Animal Care (NIH Publication No. 86-23, revised in 1985) and approved by the Ethics Committee of Shandong University, China. Healthy male New Zealand rabbits, $2.5 \mathrm{~kg}$ to $3.0 \mathrm{~kg}$, were provided by Shandong University Animal Center (Jinan, China). To establish the model of ANFH, the rabbits were injected with horse serum $(10 \mathrm{ml} / \mathrm{kg})$ at the first and third weeks via the ear vein. At the fifth week, the animals were injected with methylprednisolone $(40 \mathrm{mg} / \mathrm{kg})$ intraperitoneally one time every day for three consecutive days. Ten (10) rabbits were used as normal controls, which received injections with equal volumes of saline. The model rabbits were then split into two groups: Ghrelin group (10) and Vehicle group
(10). Rabbits in the Ghrelin group were injected with Ghrelin (25ug/kg/day) intraperitoneally for 2 weeks; rabbits in Vehicle group were injected with equal volumes of saline. After 2 weeks, the rabbits were sacrificed by air embolism, and femoral heads were collected for analysis. Successful model establishment was confirmed by MRI scanning of the femoral heads.

\section{MRI scanning}

MRI scanning was conducted 2 weeks after the last methylprednisolone injection at the end of the experiments before the rabbits were sacrificed. The scanning was done using midfield magnetic field strand of 1 Tesla following general anaesthesia (pre-anaesthesia: ketamine 20-40 $\mathrm{mg} / \mathrm{kg}$ + Diazepam 1-5 $\mathrm{mg} / \mathrm{kg} \mathrm{im}$; induction: propofol 3-10 $\mathrm{mg} / \mathrm{kg}$ iv; maintenance: $1-4 \%$ inhalation).

\section{Histochemical examination}

After the rabbits were sacrificed, the femoral heads were collected quickly and fixed by $10 \%$ formalin for 24 hours, followed by decalcification in nitric acid solution (5\%) for 7 days. After paraffin-embedding, slices of $5 \mu \mathrm{m}$ were made for hematoxylin-eosin staining (HE) staining. Histochemical examination was conducted under a microscope (Olympus CX31, Japan). Ten (10) randomly selected fields from each slice were observed and photographed.

\section{Real time qRT-PCR}

After washing with PBS, femoral head sample was frozen in liquid nitrogen, and then grinded in a mortar until it became powder. Total RNA was extracted using RNAios Kit (Takara, Shanghai, China) following the manufacturer's guide. An aliquot of $1 \mu \mathrm{g}$ of RNA was reverse-transcribed into cDNA at $42^{\circ} \mathrm{C}$ for 40 min with $200 \mathrm{U}$ of $\mathrm{M}$ $M L V$ reverse-transcriptase $(\mathrm{MBI})$ and $0.5 \mu \mathrm{g}$ of oligo (dT) primers in a $20 \mu \mathrm{l}$ reaction mixture. Aliquot of $2 \mu \mathrm{l}$ cDNA was added to $1 \times$ TaqMan buffer (Takara, Shanghai, China). The PCR was done at the following conditions: pre-denaturation for $3 \mathrm{~min}$ at $95^{\circ} \mathrm{C}$, and then 40 cycles of denaturation for $60 \mathrm{~s}$ at $93^{\circ} \mathrm{C}$, annealing for $60 \mathrm{~s}$ at $55^{\circ} \mathrm{C}$, elongation for $60 \mathrm{~s}$ at $72^{\circ} \mathrm{C}$. The corresponding melting curve analysis was done at $95^{\circ} \mathrm{C}$. The $\mathrm{mRNA}$ levels were analysed using a comparative $\mathrm{Ct}$ method (Applied Biosystems; CA, USA). The target gene expressions were normalized to $\beta$-actin. The primers were designed on Primer Express $₫$ software (Applied Biosystems) and the sequences are: $\beta$-actin, Forward: 5'-tgcgggacatcaaggagaa-3'; Reverse 5'-aggaaggagggctggaaca-3'; Vascular endothe- 
lial growth factor (VEGF), Forward, 5'-aatgatg aaagcctggagtgtg-3'; Reverse: 5'-tcacatttgttgtgctgt aggaag-3'; Bone Morphogenetic Protein 2 (BMP2), Forward, 5'-tttggtcaactccgtgaactctaa -3'; Reverse, 5'- acacccacaaccctccaca-3'.

\section{Statistical analysis}

All data were presented as mean \pm SEM. Comparison of mean was done using analysis of variance (ANOVA) and Newman-Keuls test. SPSS 13.0 software was used for all statistical analysis. A $p$ value less than 0.05 was considered statistically significant.

\section{RESULTS}

\section{Evaluation of the avascular necrosis of femoral head}

MRI scanning was conducted to evaluate the avascular necrosis of the femoral head upon the establishment of ANFH model and after ghrelin treatment. The Control group displayed schistic signal in T1 weight imaging and normal signal in T2 weight imaging, and no liquid signal was detected in the hip joint cavity. In the Vehicle group, it displayed schistic long signal in T1 weight imaging and slightly long signal in T2 weight imaging. Obvious liquid signal was detected in the hip joint cavity, suggestive of bilateral avascular necrosis. Compared with the Vehicle group, all of these changes were attenuated in Ghrelin group (Figure 1).

\section{Effect of ghrelin on femoral head avascular necrosis}

To further evaluate the effect of ghrelin on femoral head avascular necrosis, histochemical staining was conducted after treatment and the results obtained are shown in Figure 2 . In the control group, bone trabecula were arranged regularly and tightly. The cells in cortical bone and bone trabecula were clearly visible with nucleus in the center. Blood vessels were affluent and the adipocytes were sparse in the bone marrow without fusion phenomenon. In Vehicle group, the hierarchy of cartilage was generally normal. The nucleus of cells in cortical bone and bone trabecula were concentrated, and located on one side. Empty bone lacunae were increased. Bone trabecula was sparse, slender and incomplete. In the bone marrow, the number of hematopoietic cells were reduced, whereas the number of adipocytes was increased with evident fusion phenomenon. Compared with the vehicle group, all of these changes were improved in Ghrelin group.

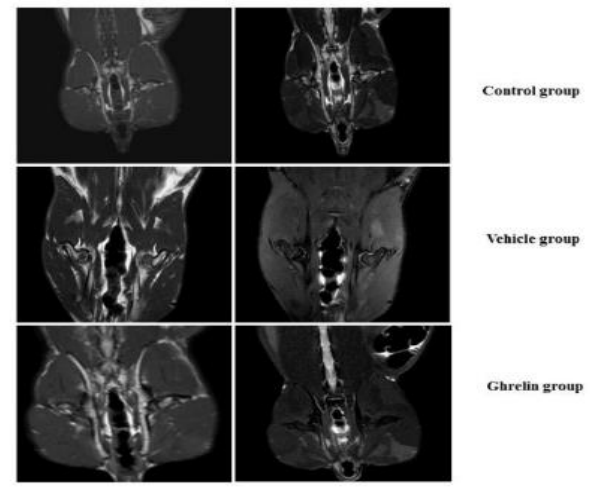

Figure1: MRI scan of the femoral head of rabbits. After treatment, femoral head avascular necrosis was evaluated by MRI scanning. Representative photos from each group were shown. T1: T1 weight imaging (left panel); T2: T2 weight imaging (right panel)

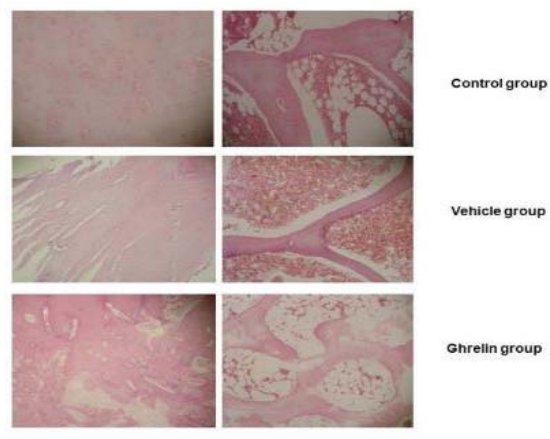

Figure 2: Histochemical analysis of femoral head tissues of rabbits. After treatment, femoral head avascular necrosis was evaluated by histochemical staining. Representative photos from each group were shown. (Magnification 400X)

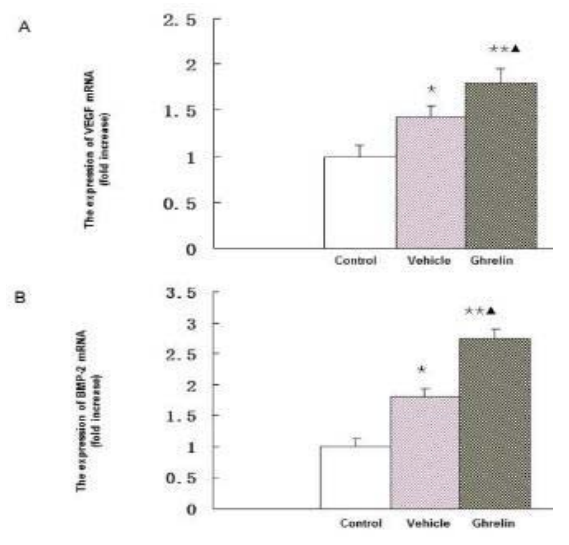

Figure 3: Effects of ghrelin on mRNA expressions of VEGF and BMP-2. After treatment, the mRNA expressions of VEGF and BMP-2 were determined by real time RT-PCR. (A) VEGF mRNA expression in each group $(n=3)$. (B) BMP-2 mRNA expression in each group ( $n=3)$. ${ }^{*} P<0.05$, vs. Control group, ${ }^{*} P<$ 0.01 , vs. Control group; $\wedge p<0.05$, vs. vehicle group 


\section{Effects of Ghrelin on VEGF and BMP-2 mRNA expression}

Compared with the control group, the mRNA levels of VEGF and BMP-2 in the femoral head tissues were significantly increased in vehicle group. In Ghrelin group, the mRNA levels of VEGF and BMP-2 were further increased compared to Vehicle group as shown in Figure 3.

\section{DISCUSSION}

Avascular necrosis of the femoral head (ANFH) is a common and disabling disease in older people, especially those with exposure to corticosteroid and alcohol abuse. So far, the effectiveness of available therapeutic measures for ANFH is unsatisfactory. Ghrelin is a 28amino-acid peptide that is primarily produced in the stomach, where it is synthesized and secreted from a distinct endocrine cell types in the submucosal layer [3,13-15]. Ghrelin is a natural ligand of the growth hormone secretagogue receptor [3] through which ghrelin stimulates the release of growth hormone $[16,17]$.

In the present study, we examined the effect of ghrelin on steroid-induced ANFH in a rabbit model. After the establishment of the Control, Vehicle and Ghrelin groups, the observations from the MRI scan revealed certain cellular and anatomical features, which suggested bilateral avascular necrosis in the vehicle group, but there was significant improvement of these changes in the Ghrelin group. A similar trend was also observed for the histochemical analysis. The results obtained suggested that ghrelin had beneficial effects in the repair process following femoral head avascular necrosis.

To date, multiple mechanisms have been proposed for the pathogenesis of steroid-induced ANFH. VEGF is one of the most potent proangiogenic growth factors identified so far. A previous study showed that VEGF produced by the chondrocytes in human neonatal growth plate cartilage plays a role in the regulation of vascular invasion of the growth plate [18]. In addition to its effect on blood vessel formation, VEGF has been shown to promote the repair of bone by enhancing osteoclastic bone resorption and survival of mature osteoclasts [19]. Bone morphogenetic protein-2 (BMP-2) is another growth factor that has been implicated to be produced in the bone tissues, which can stimulate the proliferation and differentiation of bone precursor cells in autocrine and paracrine manners. Both in vitro and in vivo studies showed that BMP-2 plays important roles in bone formation, growth and repair [20,21]. In BMP-2deficient mice, the earliest steps of bone fracture healing is often blocked [22].

To explore the possible mechanism, we examined the effect of ghrelin on BMP-2 and VEGF expressions. In the present study, our results showed that ghrelin treatment significantly increased BMP-2 and VEGF expressions in the femoral head. BMP-2 expression was upregulated 2 weeks after the induction of ANFH. In spite of this, the precise mechanism is unclear. It is possible that the up-regulation of BMP-2 after ANFH induction could be a physiological response to initiate bone repair.

The up-regulation of BMP-2 following ANFH was further enhanced by ghrelin treatment. Similarly, VEGF expression was also up-regulated following ANFH, which was enhanced by ghrelin treatment. These results are in line with a previous study which showed that ghrelin upregulated VEGF expression in the skin capillary endothelial cells in mice. These findings suggest that ghrelin may promote bone repair after $\mathrm{ANFH}$, at least partly through the up-regulation of VEGF and BMP-2.

\section{CONCLUSION}

Our results indicated that ghrelin has a beneficial effect on the healing process of steroid-induced ANFH. A possible mechanism may be through the induction of VEGF and BMP-2 expression. These findings raise the possibility of using ghrelin as a drug in the treatment of ANFH in clinical setting.

\section{DECLARATIONS}

\section{Acknowledgement}

The authors wish to thank Professor Yuantao Liu (Department of Endocrinology, the Second Hospital of Shandong University, Jinan, Shandong Province, China) for English language editing and writing assistance.

\section{Funding}

This work was supported by Youth Fund of the 2nd Hospital of Shandong University (grant number: Y2014010016).

\section{Conflict of interest}

No conflict of interest is associated with this work. 


\section{Contribution of authors}

We declare that this work was done by the author(s) named in this article and all liabilities pertaining to claims relating to the content of this article will be borne by the authors. All authors read and approved the manuscript for publication.

\section{Open Access}

This is an Open Access article that uses a funding model which does not charge readers or their institutions for access and distributed under the terms of the Creative Commons Attribution License (http://creativecommons.org/licenses/by/ 4.0) and the Budapest Open Access Initiative (http://www.budapestopenaccessinitiative.org/rea d), which permit unrestricted use, distribution, and reproduction in any medium, provided the original work is properly credited.

\section{REFERENCES}

1. Kerachina $M$, Harvev $E$, Coernover $D$, Chow $T$ and Séguin C. Avascular necrosis of the femoral head: vascular hypotheses. J Endothelium, 2006; 13(4):23744.

2. Kerachian MA, Séguin $C$ and Harvey E. Glucocorticoids in osteonecrosis of the femoral head: a new understanding of the mechanisms of action. J Steroid Biochem Mol Biol, 2009; 114:121-128.

3. Kojima M, Hosoda H, Date Y, Nakazato M, Matsuo $H$ and Kangawa K. Ghrelin is a growth-hormone-releasing acylated peptide from stomach. Nature, 1999; 402:65660.

4. Tschop M, Smiley $D$, Heiman $M$. Ghrelin induces adiposity in rodents. Nature, 2000; 407:908-913.

5. Cummings $D$ and Shannonm M. Roles for Ghrelin in the regulation of appetite and body weight. Arch Surg, 2003;138 (4):389-386.

6. Horvath $T$, Dino S, Sotonyi P. Heiman $M$ and Tschöp $M$. Minireview: Ghrelin and the regulation of energy balance. A hypothalamic perspective. Endocrimology, 2011; 142(10):4163-4169.

7. Nikolopoulo D, Theocharis $S$ and Kouraklis G. Ghrelin, another factor affecting bone metabolism. Med Sci Monit, 2010; 16(7):RA147-62.

8. Van der Velde $M$, van der Eerden B, Sun $Y$, Almering $J$, van $\operatorname{der}$ Lely $A$, Delhanty $P$, et al. An age-dependent interaction with leptin unmasks Ghrelin's bone-protective effects. Endocrinology, 2012; 153,3593-3602.

9. Van der Eerden B, Karperien M and Wit J. Systemic and local regulation of the growth plate. Endocr Rev, 2003; $24,782-801$
10. Shimizu Y, Nagaya N, Teranishi Y, Imazu M, Yamamoto $H$, Shokawa $T$, et al. Ghrelin improves endothelial dysfunction through growth hormone-independent mechanisms in rats. Biochem Biophys Res Commun, 2003; 310:830-835.

11. Nagaya N, Moriya J, Yasumura Y, Uematsu M, Ono F, Shimizu W, et al. Effects of Ghrelin administration on left ventricular function, exercise capacity, and muscle wasting in patients with chronic heart failure. Circulation, 2004;110:3674-3679.

12. Rezaeian F, Wettstein R, Scheuer C, Bäumker K, Bächle $A$, Vollmar B, et al. Ghrelin protects musculocutaneous tissue from ischemic necrosis by improving microvascular perfusion. Am J Physiol Heart Circ Physiol, 2012; 302(3):H603-10.

13. Date $Y$, Kojima M, Hosoda H, Sawaguchi A, Mondal M, Suganuma $T$, et al. Ghrelin, a novel growth hormonereleasing acylated peptide, is synthesized in a distinct endocrine cell type in the gastrointestinal tracts of rats and humans. Endocrinology, 2000; 141:4255-61.

14. Date Y, Murakami N, Kojima M, Kuroiwa T, Matsukura S, Kangawa $K$, et al. Central effects of a novel acylated peptide, Ghrelin, on growth hormone release in rats. Biochem Biophys Res Commun, 2000; 275:477-80.

15. Gualillo O, Caminos J, Kojima M, Kangawa K, Arvat E, Ghigo $E$, et al. Gender and gonadal influences on Ghrelin mRNA levels in rat stomach. Eur J Endocrinol, 2001; 144:687-90.

16. Korbonits $M$, Ciccarelli E, Ghigo $E$ and Grossman A. The growth hormone secretagogue receptor. Growth Horm IGF Res 9 Suppl, 1999; A:93-9.

17. Bowers $C$. Unnatural growth hormone-releasing peptide begets natural Ghrelin. J Clin Endocrinol Metab, 2001; 86:1464-9.

18. Horner A, Bishop N, Bord S, Beeton C, Kelsall A, Coleman $N$, et al. Immunolocalisation of vascular endothelial growth factor (VEGF) in human neonatal growth plate cartilage. J Anat, 1999; 194 (4):519-24

19. Nakagawa $M$, Kaneda $T$, Arakawa $T$, Morita $S$, Sato $T$, Yomada $T$, et al. Vascular endothelial growth factor (VEGF) directly enhances osteoclastic bone resorption and survival of mature osteoclasts. J FEBS Lett, 2000; 473 (2): 1612-164.

20. Kloen P, Doty SB, Gordon E, Rubel IF, Goumans M and Helfet $D$. Expression and activation of the BMPsignaling components in human fracture non-unions. $J$ Bone Joint Surg Am, 2002; 84-A (11):1909 - 1918.

21. Kugimiya $F$, Kawaguchi $H$, Kamekura S, Chikuda $H$, Ohba S, Yano F, et al. Involvement of endogenous bone morphogenetic protein (BMP) 2 and BMP6 in bone formation. J Biol Chem, 2005; 280 (42):35704- 35712.

22. Tsuji K, Bandyopadhyay A, Harfe B, Cox K, Kakar S, Gerstenfeld $L$, et al. BMP-2 activity, although dispensable for bone formation, is required for the initiation of fracture healing. Nat Genet, 2006; 38(12):1424-9.

Trop J Pharm Res, October 2020; 19(10): 2101 